\title{
Prevalence of Medication
}

\section{Non-Adherence among Psychiatric Patients in a Tertiary Hospital in Nigeria}

\author{
Chidozie Donald Chukwujekwu*, Olufisayo Kola Adesokun \\ Department of Neuropsychiatry, University of Port Harcourt Teaching Hospital, Port Harcourt, Nigeria \\ Email: *chukwujekwu@uniport.edu.ng
}

How to cite this paper: Chukwujekwu, C.D. and Adesokun, O.K. (2017) Prevalence of Medication Non-Adherence among Psychiatric Patients in a Tertiary Hospital in Nigeria. Journal of Biosciences and Medicines, 5, 1-10.

https://doi.org/10.4236/jbm.2017.54001

Received: March 23, 2017

Accepted: April 23, 2017

Published: April 28, 2017

Copyright $\odot 2017$ by authors and Scientific Research Publishing Inc. This work is licensed under the Creative Commons Attribution International License (CC BY 4.0).

http://creativecommons.org/licenses/by/4.0/

(c) $\underset{\mathrm{EY}}{\text { (i) Open Access }}$

\begin{abstract}
Background: The consequences of non-adherence to prescribed medications by psychiatric patients for both patients and the health care system are myriad and grave. Aim: The study was designed to ascertain the prevalence of medication non-adherence among psychiatric patients and identify factors that aid this malady. Methods: This prospective, cross-sectional study was carried out within a 4 month period at the out-patient psychiatric clinic of the University of Port Harcourt Teaching Hospital; using the Medication Adherence Rating Scale (MARS) and a self designed questionnaire containing socio-demographic and psychiatric illness variables. Results: A total number of 111 patients who participated in the study were analyzed. The cohort comprises $22(19.8 \%)$ schizophrenics, 38 (34.2\%) mood disorder patients, 24 (21.6\%) anxiety disorder patients, $10(9.0 \%)$ patients suffering from substance abuse and 17 (15.3\%) with other psychiatric diagnoses (somatoform and personality disorders). Most of the patients were male (53;47.7\%), aged between 21 - $30 \mathrm{yrs}$ ( $44 ; 39.6 \%)$, unemployed $(38 ; 34.2 \%)$, as single $(58 ; 52.3 \%)$. The prevalence of non-adherence to medications among the cohort studied is $39.6 \%$. There was a significant association between consistency in taking one's medications and MARS scores but none between socio-demographic variables and MARS score. Conclusion: The rate of medication non adherence among the subjects in this study was $39.6 \%$. The three most important reasons reported for this behaviour include: Feeling that they had recovered from their illness and hence have been cured, belief that their illness was of a spiritual origin and hence would not be amenable to orthodox medicine and the side effects of the medications. Non adherence to medication increases the risk of psychiatric morbidity and mortality and efforts at curbing this trend must be eclectic.
\end{abstract}




\section{Keywords}

Medication, Non-Adherence, Psychiatric, Prevalence, Subject

\section{Introduction}

Adherence can be defined as the active, voluntary and collaborative involvement of the patient in a mutually acceptable course of behaviour to produce, a therapeutic result [1] [2]. Medication adherence behaviour therefore refers to compliance by patients in taking their prescribed medications as instructed by their doctors (adherence) as well as continuing to carry out their instruction throughhout the duration of drug therapy (persistence) [3] [4]. In other words, adherence is a concept that describes the patients' acceptance and understanding of the need to be treated willingly and manifests the degree of this acceptance and understanding with a positive or negative attitude towards drugs prescribed for the patient.

Medication adherence is a growing concern to clinicians, the health care system and other stakeholders because of the mountain of evidence that non-adherence is prevalent and associated with adverse outcomes and higher costs of care [5]. It has been reported that adherence to medications for most chronic physical conditions significantly drop after 6 months of treatment [5].

In Psychiatry, non-adherence is a significant problem. Studies show that between a third and half of medicines that are prescribed for long term conditions are not used as recommended [6].

In the case of schizophrenia, almost $76 \%$ of the sufferers became non-compliant to the medication within the first 18 months of treatment [7].

The consequences of non adherence for both patients and the health care system are myriad and grave. Increased morbidity and mortality with their associated cascade of challenges readily come to mind. On the other hand if the issues of non adherence are identified and addressed actively, it has the potential of improving the mental health of patients and will reduce the burden of cost of mental health services [8].

There is a lack of consensus on the standard definition for non-adherence. While some studies opine that a rate of $>50 \%$ compliance to prescribed medications suggests adequate adherence, other researchers insist on a compliance rate of at least $95 \%$ [8].

Unlike in the developed world, there is paucity of studies on medication adherence done in the underdeveloped world. This is not surprising because ignorance, myth solely based on tradition and superstition, negatively shape the attitude of most people towards the etiology and solutions of most illnesses, especially mental disorders in this part of the world [9].

The urgent need to $\mathrm{X}$ ray the virgin area of non-adherence to medications in the underdeveloped world as well as the recommendation by WHO that clinicians have the responsibility to identify such issues as non-adherence and im- 
prove collaborative relationships among multidisciplinary teams to deliver a better clinical and cost-effective service [10] gave impetus for this work.

\section{Methodology}

A prospective, cross-sectional study of 111 psychiatric out-patients of the University of Port Harcourt Teaching Hospital (UPTH) was carried out within a 4 month period (from Feb-May 2013). The study took place at the outpatient psychiatric clinic of the UPTH, a tertiary health institution that provides clinical services for at least 5 states in Southern Nigeria.

\subsection{Sample Size Estimation}

Varying prevalence estimates of non-adherence to medications reported by most studies in literature range from $8 \%$ to $62 \%$ [11]. Few others have reported even higher estimates. Owing to this, as well as paucity of studies on this topic in the Niger Delta region of Nigeria, a pilot survey was done before the actual study commenced.

Out of 54 psychiatry out-patients, 4 persons were found to be non-adherent to their medications giving a pilot non-adherence rate of about $7.4 \%$. These are persons who scored 5or less out of 10 on the Medication Adherence Rating scale (MARS).

The sample size for this study was calculated using the formula for comparison of proportion:

$$
N=Z^{2} p(1-p) / d^{2}
$$

where $\mathrm{N}=$ Sample size, $\mathrm{Z}$ (normal standard deviation) $=1.96$ at $95 \%$ confidence, $\mathrm{p}=$ prevalence of non-adherence from the pilot study $(7.4 \%=0.074), \mathrm{d}=$ precision (0.05)

$$
\begin{aligned}
& N=(1.96)^{2} \times(0.074 \times 0.926) /(0.05)^{2} \\
& N=105.29
\end{aligned}
$$

Attrition $=10 \%(11)$

Final sample size $=116$

Five subjects did not complete the study; hence data from 111 subjects were analyzed.

\subsection{Instruments}

Instruments employed in the study comprise the medication adherence rating scale (MARS) and a self designed questionnaire containing socio-demographic and psychiatric illness variables.

MARS was developed by Thompson et al in 1999 as a quick self report measure of adherence to neuroleptic medications. It was derived from a 4 item Morisky medication adherence questionnaire (MAQ) and a 30 item Dry attitude inventory (DAI) [8].

The validity and reliability of MARS has been established by Thompson et al. and then Flako et al. in 2008 in a large study and has been reported to be ade- 
quate [12] [13]. MARS focuses on the attitude of patients to their medications as well as on adherence. It comprises questions about how frequently they forget to take their medications, whether they feel well or unwell when they do, whether they take medication when they are sick, whether they believe that it is natural for their thoughts to be troubled by medications or not and the unwanted effects of medication on them. The questionnaire also ascertains their belief in the ability of the medication to prevent them from getting sick when they are compliant on them.

The self-designed questionnaire, contains questions that ask the patient about their current medications and dosage schedule. It also seeks to ascertain if the medication makes them feel suicidal, causes weight gain, makes them aggressive, cause sleep disturbances or sexual side effects.

\subsection{Procedure}

Before the commencement of the study, information was obtained from the patients to be involved in the research. Where the patient was not in a position to give consent, arising to his or her mental status, consent was sought from a reliable accompanying relation. The process entailed giving adequate information to the patients and relations about the nature and purpose of this study. Every patient was informed that he/she had the right to participate or withdraw from the study at any time without any risk to his/her treatment. Every third psychiatric outpatient that came to the psychiatric clinic between February and May2013 were included in the study.

The two instruments listed above were administered to each participant. A score of less than 6 on MARS in generally considered as a poor level of adherence (i.e. non adherence) [8].

\subsection{Data Analysis}

The data was analyzed using the statistical package for Social Sciences (SPSS) at $5 \%$ level of significance and $95 \%$ confidence interval. Frequency distribution charts were employed to determine prevalence of medication non adherence among the various sub groups of psychiatric patients. Analysis of variance (ANOVA) was used is test for significance of non-adherence among the various groups. T-test was used to assess continuous variables while chi-square test was used for categorical variables

\section{Results}

One hundred and eleven (111) patients who completed the study were analyzed. The cohort consist of $19.8 \%$ schizophrenics, $34.2 \%$ patients suffering from mood disorders, $21.6 \%$ from anxiety disorders, $9.0 \%$ from psychiatric and $15.3 \%$ from other psychiatric conditions such as somatoform and personality disorders. The diagnosis was based on the ICD 10 criteria (see Table 1).

Table 2 shows the distribution of the subjects based on their socio-demographic profile. 58(52.3\%) patients were males; $53(47.7 \%)$ were females. The bulk of 
Table 1. Distribution of frequencies of various diagnostic categories among the study cohort. $\mathrm{N}=111$ patients.

\begin{tabular}{|c|c|c|}
\hline \multicolumn{2}{|c|}{ FREQUENCY DIAGNOSIS } & $\%$ \\
\hline Schizophrenia & 22 & 19.8 \\
\hline Mood disorder & 38 & 34.2 \\
\hline Anxiety disorder & 24 & 21.6 \\
\hline Substance abuse & 10 & 9.0 \\
\hline Others & 17 & 15.3 \\
\hline Total & 111 & 100 \\
\hline
\end{tabular}

Table 2. Distribution of frequencies of participants based on socio-demographic characteritics. $\mathrm{N}=111$ patients.

\begin{tabular}{|c|c|c|}
\hline \multicolumn{2}{|l|}{ FREQUENCY } & $\%$ \\
\hline \multicolumn{3}{|c|}{ SOCIO-DEMOGRAPHIC CHARACTERISTICS } \\
\hline \multicolumn{3}{|l|}{ (A) SEX } \\
\hline Male & 58 & 52.3 \\
\hline Female & 53 & 47.7 \\
\hline \multicolumn{3}{|c|}{$(\mathrm{x} 2=0254, \mathrm{df}=1, \mathrm{p}>0.05)$} \\
\hline \multicolumn{3}{|c|}{ (B) AGE (yrs) } \\
\hline $11-20$ & 4 & 3.6 \\
\hline $21-30$ & 44 & 39.3 \\
\hline $31-40$ & 27 & 24.3 \\
\hline $41-50$ & 22 & 19.8 \\
\hline $51-60$ & 9 & 8.1 \\
\hline Above 60 & 5 & 4.5 \\
\hline \multicolumn{3}{|c|}{$(\mathrm{x} 2=0.180, \mathrm{df}=1, \mathrm{p}>0.05)$} \\
\hline \multicolumn{3}{|l|}{ (C) EMPLOYMENT } \\
\hline Unskilled labour (technician) & 15 & 13.5 \\
\hline Skilled labour (trader) & 31 & 27.9 \\
\hline Professional & 27 & 24.3 \\
\hline Unemployed & 38 & 34.2 \\
\hline \multicolumn{3}{|c|}{$(\mathrm{x} 2=0.986, \mathrm{df}=1, \mathrm{p}>0.05)$} \\
\hline \multicolumn{3}{|c|}{ (D) MARITAL STATUS } \\
\hline Single & 65 & 58.6 \\
\hline Separated/divorced & 15 & 13.5 \\
\hline Married & 28 & 25.2 \\
\hline Widowed & 3 & 2.7 \\
\hline \multicolumn{3}{|c|}{$(\mathrm{x} 2=0.062, \mathrm{df}=1, \mathrm{p}>0.05)$} \\
\hline \multicolumn{3}{|c|}{ (E) LITERACY STATUS } \\
\hline Illiterate & 6 & 5.4 \\
\hline Primary education & 8 & 7.2 \\
\hline Secondary education & 38 & 34.2 \\
\hline Tertiary education & 58 & 52.3 \\
\hline \multicolumn{3}{|c|}{$(\mathrm{x} 2=0.554, \mathrm{df}=3, \mathrm{p}>0.05)$} \\
\hline \multicolumn{3}{|c|}{ (F) RELIGION } \\
\hline Christian & 104 & 93.7 \\
\hline Muslim & 4 & 3.6 \\
\hline Traditional & 2 & 1.8 \\
\hline Others & 1 & 0.9 \\
\hline \multicolumn{3}{|c|}{$(\mathrm{x} 2=0.943, \mathrm{df}=1, \mathrm{p}>0.05)$} \\
\hline Total & 111 & 100 \\
\hline
\end{tabular}


the subjects were aged between 21 - 30 yrs (44; 39.6\%) and 31-40yrs (27; 24.3\%). The least number were teenagers $11-20$ years $(4 ; 3.6 \%)$.

The greatest proportion of the subjects was unemployed $(38 ; 34.2 \%) 31$ (27.9\%) were skilled labourers, 27 (24.3\%) were professionals and $15(13.5 \%)$ were unskilled laborers. Most 65 (58.6\%) were single; 58 (52.3\%) had tertiary education and 104 (93.7\%) were Christians. There was no significant association between socio-demographic variables and MARS scores.

Table 3 shows the distribution of frequency of the subjects based on psychiatric illness variables and MARS scores.

The greatest percentages of the patients had suffered their illness between 1 - 5 yrs $(43 ; 38.7 \%)$ and $5 y-10 y r(33 ; 29.7 \%)$. Most of the respondents reported that their doctor influenced them most to adhere to their medications $(57 ; 51.4 \%)$ and were least influenced in this regard by their pastor/rev father $(2 ; 1.8 \%)$. Most of them $(86 ; 77.5 \%)$ reported that no one in particular discouraged them from adhering to their medications. The greatest percentage 40 (36\%) and 39(35.1\%) claimed they stopped taking their medications because they felt they had recovered and that their medications no longer worked for them respectively. When questioned on what they didn't like about their medication, most of the subjects $85(76.6 \%)$ answered "nothing definite". Most of the patients $72(64.9 \%)$ claimed that they consistently took their medications while $33(29.7 \%)$ reported that they were fairly consistent. The least $6(5.4 \%)$ reported that they were inconsistent in taking their medications. $67(60.4 \%)$ were adherent to their medications (i.e. they scored MARS score of 6 or more). While 44 (39.6\%) were non-adherent (MARS score of less than 6; therefore the prevalence of non adherence to medications is about 40\%). There is significant association between consistency in taking one's medication and the MARS score. $\mathrm{X}^{2}=2.668, \mathrm{df}=2, \mathrm{p}<0.05$.

This is the only positive statistically positive association seen in this study.

\section{Discussion}

The aim of this study was to ascertain the factors that aid non adherence to medications and hence examine the attitude of patients towards their medications.

The study shows that the prevalence of non adherence to medication by the patient is $40 \%$. This agrees with previous studies where rates of $24 \%$ - $92 \%$ have been reported by various authors [14] [15] [16]. Some others have yet reported a different range of $8 \%-62 \%(11)$.

This study also showed that doctors (51.4\%) influenced the patients most to adhere to their prescribed medications while nurses account for only $10.8 \%$ (13). The need for all health workers, not only doctors, to be involved in advising patients to adhere to their medications is therefore underscored.

The two most outstanding reasons for not adhering to prescribed medications were "feeling that they have recovered" (40.36\%) and "believing that the cause of their illness is spiritual" and hence wouldn't be amenable to chemotherapy (39; $25.1 \%)$. This is not surprising because in this part of the word, ignorance and myth solely based on tradition, superstition and religion affects the response of 
Table 3. Distribution of frequencies of participants based on psychiatric illness variables and mars scores. $\mathrm{N}=111$.

FREQUENCY

\section{(A) Duration Of Illness}

$$
0-2 \mathrm{mths}
$$

$2 \mathrm{mths}-1 \mathrm{yr}$

$1 \mathrm{yr}-5 \mathrm{yrs}$

5 yrs -10 yrs

$>10 y r s$
$\%$

17.1

10.8

38.7

29.7

0.9

$(\mathrm{x} 2=1.066, \mathrm{df}=4, \mathrm{p}>0.05)$

(B) Who influenced you to adhere to your medication

Doctor

Nurse

Pastor/Rev Father

Parents/Relation

Friend/Associative

Others

None

$\begin{array}{cc}57 & 51.4 \\ 12 & 10.8 \\ 2 & 1.8 \\ 24 & 21.6 \\ 6 & 5.4 \\ 3 & 42.7 \\ 7 & 6.3\end{array}$

$(\mathrm{x} 2=1.246, \mathrm{df}=5, \mathrm{p}>0.05)$

(C) Who discouraged you from adhering

Nobody

Health workers

Pastor/Rev Father

Parents/Relations

Friends

Others

$(\mathrm{x} 2=2.225, \mathrm{df}=4, \mathrm{p}>0.05)$

(D) Reasons for stopping medication

I feel I have recovered $\quad 40 \quad 36.0$

The drugs don't work

9.0

11.7

I am afraid may become addicted to the drug

26.3

I don't like the drug (it gives meside-effects)

My sickness is spiritual

$(\mathrm{x} 2=1.020, \mathrm{df}=4, \mathrm{p}>0.05)$

(E) what I don't like about the drug

Makes me suicidal

Causes weight gain

Makes me aggressive

I didn't like the form and size of the tablet

Causes sexual side effects

Nothing definite

$(\mathrm{x} 2=1.378, \mathrm{df}=5, \mathrm{p}>0.05)$

(F) Consistence in taking your medication

(patient subjective assessment)

$\begin{array}{ccc}\text { Very consistent } & 72 & 64.9 \\ \text { Fairly consistent } & 33 & 29.7 \\ \text { Not consistent } & 6 & 5.4\end{array}$

$(\mathrm{x} 2=2.668, \mathrm{df}=2, \mathrm{p}<0.05)$

(G) MARS Score

$\begin{array}{ccc}\text { Adherent } & 67 & 60.4 \\ \text { Non adherent } & 44 & 39.6 \\ \text { Total } & 111 & 100\end{array}$


patients to their illness as well as approach towards resolving their health challenges [17] [18]. Studies show that stigma is the major reason why sufferers of mental illness fail to acknowledge their illness and is the underlying factor militating against the social reintegration of those recovering from mental illness and that stigmatizing attitudes cut across culture [19] [20] [21]. Unlike in some other studies done in Asia \& Europe [8] where major reasons for non-adherence were attributed to side effects of the medication, only $6.3 \%$ (7) of subjects in this study cited this as reason for their non-adherence to prescribed medication.

This further buttresses the varying views of etiology of mental illness and hence solution to this challenge across cultures. In Africa represented by this study, belief that the etiology of their illness is spiritual and hence would require a spiritual solution is stronger than in Asia and Europe.

Furthermore, $64.9 \%$ (72) and 33(29.7\%) of the subjects reported that they are very consistent and fairly consistent with taking their medication respectively whereas the $39.6 \%$ (44) were discovered to be non adherent to their medications judging by MARS scores. This reflects an appreciable variance between subjective and objective claims to adherence and non-adherence to medication. Moreover, there is significant association between consistency in taking one's medication and MARS scores. This implies that the more one is consistent in taking one's medication, the higher will be the MARS scores. This suggests that the MARS is a valid instrument for assessing adherence/non adherence to prescribed medications.

\section{Conclusion}

Non adherence to prescribed medications places patients at a significant risk of exacerbation of symptoms of mental illness, subsequent relapse and hence rehospitalization. Therefore, the initial step towards designing effective intervention would be to identify the risk factors for non-adherence and consistent efforts made at addressing them. Such effort must be borne by all stakeholders in this matter as well as by our traditional and religious institutions.

\section{Limitation}

The cross-sectional nature of this study does not fully allow for inference on the exact causes of non-adherence to medications among psychiatric patients. Therefore, its application to the general population should be done with caution. More longitudinal studies that would examine non-adherence to specific medications, in different settings, and which would take into cognizance, the sociocultural attributes of the patients and presence of other co-morbid illnesses are recommended. Such studies would also take into account, the number of medications taken by each patient and the duration of use.

\section{References}

[1] Delamater, A.M. (2006) Improving Patient Adherence. Clinical Diabetes, 24, 71-77. https://doi.org/10.2337/diaclin.24.2.71 
[2] Meichenbaum, D. and Turk, D.C. (1987) Facilitating Adherence: A Practitioner's Guidebook. Plenum Press, New York.

[3] Cramar, J.A., Roy, A., Burell, A., Fairchild, C.J., Fuldeore, M.J., Ollendorf, D.A. and Wong, P.K. (2008) Medication Compliance and Persistence: Terminology and Definitions. Value in Health, 11, 44-47. https://doi.org/10.1111/j.1524-4733.2007.00213.x

[4] Caetano, P.A., Lam, J.M. and Morgan, S.G. (2006) Toward a Standard Definition and Measurement of Persistence with Drug Therapy: Examples from Research on Station and Antihypertensive Utilization. Clinical Therapeutics, 28, 1411-1424. https://doi.org/10.1016/j.clinthera.2006.09.021

[5] Osterberg, L. and Blaschike, T. (2005) Adherence to Medication. The New England Journal of Medicine, 353, 487-497. https://doi.org/10.1056/NEJMra050100

[6] Haynes, R.B., McDonald, H., Garg, A.X. and Montague, P. (2002) Interventions for Helping Patients to Follow Prescription for Medications. The Cochrane Database of Systematic Reviews, No. 2. Article No. CD000011.

[7] Yong, J.L., Zonana, H.V. and Shepler, L. (1986) Medication Noncompliance in Schizophrenia: Codification and Update. The Bulletin of the American Academy of Psychiatry and the Law, 14, 105-122.

[8] Abrar, S., Shoka, A., Arain, N. and Widuch-Mert, C. (2012) Landing on the MARS!!! British Journal of Medical Practitioners, 5, a523.

[9] Chukwujekwu, D.C. and Stanley, P.C. (2008) Patterns of Aggression among Psychiatric In-Patients at The Jos University Teaching Hospital. Journal of Medicine in the Tropics, 10, 7-13.

[10] World Health Organization (2003) Adherence to Long-Term Therapies: Evidence for Action. http://apps.who.int/medicinedocs/en/d/Js4883e/5.html

[11] Timmerman, L., Strunks, D.L., Groeneweg, J.G. and Huggen, F.J. (2016) Prevalence and Determinants of Medication Non-Adherence in Chronic Pain Patients, a Systematic Review. Acta Anaesthesiologica Scandinavica, 60, 416-431. https://doi.org/10.1111/aas.12697

[12] Thompson, K., Kulkarni, J. and Sergeiew, A.A. (2000) Reliability and Validity of a New Medication Adherence Rating Scale (MARS) for the Psychoses. Schizophrenia Research, 42, 241-247. https://doi.org/10.1016/S0920-9964(99)00130-9

[13] Fialko, L., Garety, P.A., Kniers, E., Dunn, G., Bebbington, P.E., Fowler, D. and Freman, D. (2008) A Large Scale Validation Study of the Medication Adherence Rating Scale (MARS). Schizophrenia Research, 100, 53-59. https://doi.org/10.1016/j.schres.2007.10.029

[14] Gilmer, T.P., Dolder, C.R, Lacro, J.P., Folsim, D.P., Lindamer, L., Garcia, P. and Jeste, D.V. (2004) Adherence to Treatment with Antipsychotic Medication and Healthcare Costs among Medicaid Beneficiaries with Schizophrenia. The American Journal of Psychiatry, 161, 692-699. https://doi.org/10.1176/appi.ajp.161.4.692

[15] Hibaye, G., Dessarlegne, Y., Debero, N., Bekan, L. and Sintayehu, M. (2013) Prevalence of Drug Non Adherence and Associated Factors among Patients with Bipolar Disorder at Outpatient Unit of Amanuel Hospital, Addis Ababa, Ethiopia, 2013. Journal of Psychiatry, S1, 003.

[16] Mukattash, T.L., Alzounbi, K.H., Abu El-Rub, E., Jarab, A.S., Al-Azzam, S.L., Khdour, M., Shara, M. and Al-Hamarneh, Y.N. (2016) Prevalence of Non-Adherence among Psychiatric Patients in Jordan, a Cross Sectional Study. International Journal of Pharmacy Practice, 24, 217-221. https://doi.org/10.1111/ijpp.12239

[17] Chukwujekwu D.C. and Stanley P.C. (2011) Prevalence and Correlates of Aggres- 
sion among Psychiatric in-Patients at Jos University Teaching Hospital. Nigerian Journal of Clinical Practice, 14, 163-167.

[18] Chukwujekwu, D.C., Chukwujekwu, J.C. and Olose, O.E. (2016) Comparison of Degrees of Social Distance towards the Mentally Ill between Relatives of Psychiatric Patients, Health Workers and the General Public. American Journal of Psychiatry and Neuroscience, 4, 48-51. https://doi.org/10.11648/j.ajpn.20160403.13

[19] Carne, B. (1998) A Consumer Perspective. Canadian Journal of Community Mental Health, 17, 21-28. https://doi.org/10.7870/cjcmh-1998-0016

[20] Link, B.G., Phelan, J.C. and Bresnaham, M. (1999) Public Conceptions of Mental Illness, Labels, Causes, Dangerousness and Social Distance. American Journal of Public Health, 89, 1328-1333. https://doi.org/10.2105/AJPH.89.9.1328

[21] Angermayer, M.C. and Matschinger, H. (2005) Causal Beliefs and Attitudes to People with Schizophrenia. Trend Analysis Based on Data from Two Population Surveys in Germany. British Journal of Psychiatry, 186, 331-334.

https://doi.org/10.1192/bjp.186.4.331

Submit or recommend next manuscript to SCIRP and we will provide best service for you:

Accepting pre-submission inquiries through Email, Facebook, LinkedIn, Twitter, etc. A wide selection of journals (inclusive of 9 subjects, more than 200 journals)

Providing 24-hour high-quality service

User-friendly online submission system

Fair and swift peer-review system

Efficient typesetting and proofreading procedure

Display of the result of downloads and visits, as well as the number of cited articles

Maximum dissemination of your research work

Submit your manuscript at: http://papersubmission.scirp.org/

Or contact jbm@scirp.org 